\title{
O conceito de Competências Socioemocionais nas reformas educacionais brasileiras
}

\section{The concept of Socio-Emotional Competences in Brazilian educational reforms}

\section{El concepto de Competencias Socioemocionales em las reformas educativas brasileñas}

\author{
Ademir Henrique Manfré ${ }^{1}$ \\ DOI: http://dx.doi.org/10.20435/serie-estudos.v26i57.1419
}

\begin{abstract}
Resumo: O presente artigo trata do tema Competências Socioemocionais e Educação Escolar. Ampara-se nos estudos provenientes do campo das Políticas Curriculares e visou problematizar o modelo de currículo socioemocional reconhecido como um dos pilares da Educação. O objetivo foi refletir sobre os limites da chamada Pedagogia das Competências propostas pelas reformas educacionais atuais. De acordo com a Base Nacional Comum Curricular (BNCC), por Competências Socioemocionais entende-se o conjunto de habilidades e procedimentos necessários para que o indivíduo desenvolva autoconhecimentos, capacidades de mediar conflitos e solucionar problemas cotidianos. Nessa perspectiva, a Pedagogia das Competências Socioemocionais, em contraposição à educação tradicional, surge como proposta de formação integral: afetiva, cultural, educacional, profissional. Diante do exposto, a partir do referencial teórico frankfurtiano, pretendeu-se analisar os limites da concepção educacional de Competência Socioemocional alinhada à lógica instrumental e empresarial. Partiu-se do seguinte questionamento: por que a escola é chamada a desenvolver capacidades e habilidades teóricas e práticas permeadas pela Pedagogia das Competências Socioemocionais? Concluindo, a partir da perspectiva filosófico-crítica sobre formação cultural (Bildung), apresentou-se como o imperativo econômico na Educação se traduz no que Adorno conceituou de Semiformação (Halbbildung).
\end{abstract}

Palavras-chave: competências socioemocionais; semiformação; docência.

\begin{abstract}
This article deals with the topic of Socioemotional Competences and school education. It is supported by studies in the field of Curriculum Policies and aimed to problematize the socioemotional curriculum model recognized as one of the cornerstones of Education today. The objective was to reflect on the limits of the so-called Competence Pedagogy present in current educational reforms. According to the Brazilian Common Core Curriculum (BNCC), Socioemotional Competences are understood as a set of skills and procedures necessary for the individual to develop self-knowledge, the ability to mediate conflicts, and to solve everyday problems. In this perspective, the Pedagogy of Socioemotional Competences, as opposed to a traditional education,
\end{abstract}

\footnotetext{
${ }^{1}$ Universidade do Oeste Paulista (UNOESTE), Presidente Prudente, São Paulo, Brasil.
} 
arises a proposal for integral training: affective, cultural, educational, and professional. Thus, from the theoretical framework of Frankfurt, it was intended to analyze the limits of an educational conception of socioemotional competence aligned with instrumental and business logic. It started from the following question: why is the school ascribed to develop theoretical and practical skills and abilities permeated by the Pedagogy of Socio-emotional Competences? In conclusion, from a philosophical-critical perspective on cultural formation (Bildung) it was presented how the economic imperative in Education is translated into what Adorno conceptualized as Semiformation (Halbbildung).

Keywords: socioemotional competences; semiformation; teaching.

Resumen: El presente artículo aborda el tema Competencias Socioemocionales y Educación escolar. Está respaldado por estudios en el campo de las Políticas Curriculares y tiene como objetivo problematizar el modelo curricular socioemocional reconocido como uno de los pilares de la Educación actual. El objetivo fue reflexionar acerca de los límites de la llamada Pedagogía de la Competencia presente en las reformas educativas actuales. Según la Base Nacional Común Curricular (BNCC), las Competencias Socioemocionales se entienden como un conjunto de habilidades y procedimientos necesarios para que el individuo desarrolle el autoconocimiento, la capacidad de mediar conflictos y solucionar problemas cotidianos. En esta perspectiva, la pedagogía de las competencias socioemocionales, en contraposición a la educación tradicional, aparece con una propuesta de formación integral: afectiva, cultural, educativa, profesional. Delante de lo expuesto, desde el marco teórico de la Escuela de Frankfurt, se pretendía analizar los límites de una concepción educativa de la competencia socioemocional alineada con la lógica instrumental y empresarial. Se partió de la siguiente pregunta: ¿por qué la escuela está llamada a desarrollar capacidades y habilidades teóricas y prácticas impregnadas por la Pedagogía de las Competencias Socioemocionales? En conclusión, desde una perspectiva filosófica-crítica sobre la formación cultural (Bildung) se presentó como el imperativo económico en Educación se traduce en lo que Adorno conceptualizó como Semiformación (Halbbildung).

Palabras clave: habilidades socioemocionales; semiformación; enseñanza.

\section{APRESENTANDO A TEMÁTICA}

Este ensaio trata do tema Competências Socioemocionais e Educação Escolar por meio do olhar da filosofia da Teoria Crítica da Escola de Frankfurt, mais particularmente do filósofo Theodor Adorno. É resultado de elaborações teóricas desenvolvidas na disciplina de Currículo e Escola por mim ministrada em cursos superiores de formação de professores. Trata-se, portanto, de problematizar - pela via da crítica - o modelo de currículo socioemocional reconhecido como um dos pilares da Educação hoje. Diante do exposto, o intuito é refletir sobre os limites da chamada Pedagogia das Competências presente nas reformas educacionais atuais.

Se tomarmos a Base Nacional Comum Curricular (BNCC) como referência para pensar a proposta de competências na escola, entende-se por Competências 
Socioemocionais o conjunto de habilidades e procedimentos necessários para que o indivíduo desenvolva autoconhecimentos, capacidades de mediar conflitos e solucionar problemas cotidianos (BRASIL, 2017a). Nessa perspectiva, os defensores da Pedagogia das Competências Socioemocionais apostam na formação integral: afetiva, cultural, educacional e profissional.

Não é por acaso que Perrenoud (2008) é o autor que embasa o debate sobre a Pedagogia do aprender a aprender constantemente - elementos estes, muitas vezes, desvinculados do aprender a pensar e a refletir.

Diante do exposto, a partir do referencial teórico frankfurtiano, pretendeu-se analisar os limites da concepção educacional de Competência Socioemocional alinhada à lógica instrumental e empresarial. Partiu-se do seguinte questionamento: por que a escola é chamada a desenvolver Competências Socioemocionais?

Concluindo, a partir de uma perspectiva filosófico-crítica sobre formação cultural (Bildung), apresentou-se como o imperativo econômico na Educação traduz o que Adorno conceituou de Semiformação (Halbbildung).

\section{COMPETÊNCIAS E EDUCAÇÃO: QUAL A RELAÇÃO?}

O que são competências? Como desenvolvê-las? Qual é o papel da escola na geração de competências e habilidades?

Essas questões são muito familiares àqueles comprometidos com a formação escolar, com o desenvolvimento dos estudantes, principalmente no século atual, o qual elegeu o empreendedorismo como marca da (semi)formação cultural. De modo geral, podemos dizer que competente é aquele que é capacitado, criativo, inovador, que projeta estratégias úteis que definirão o amanhã (PERRENOUD, 2008).

Nos últimos anos, a educação brasileira tem sido alvo de várias reformas ${ }^{2}$ justificadas como essenciais na geração de novas competências e habilidades profissionais. A escola tem sido chamada a responder pelas demandas do mundo do trabalho do século XXI: empreendedorismo, flexibilidade, capacidade de processar e utilizar informações de modo inovador são algumas das características que formam o perfil (semi)formativo do indivíduo contemporâneo.

2 Destacamos como documento central na análise proposta neste debate a Base Nacional Comum Curricular (BNCC), homologada em 2017. 
Kuenzer (1998) afirmou que a Pedagogia das Competências é uma corrente de pensamento muito ampla, não havendo uma unidade de entendimento a seu respeito. Utilizamos aqui o conceito definido por Perrenoud (2008, p. 45), que descreveu competência como "[...] capacidade de agir eficazmente em um determinado tipo de situação, apoiada em conhecimentos, mas sem se limitar a eles".

De acordo com Kuenzer (1998), a institucionalização do modelo de competências chega ao Brasil na década de 1990, após as organizações multilaterais - como o Banco Mundial, a Organização das Nações Unidas para a Educação, Ciência e Cultura (UNESCO) e a Organização para a Cooperação e Desenvolvimento Econômico (OCDE) - orientarem as políticas públicas e o ensino de competências e habilidades a todas as escolas do globo.

De modo geral, os modelos de competências apresentam dois focos: o primeiro refere-se às competências profissionais (cognitivas) essenciais a qualquer atividade. O segundo aponta para as Competências Socioemocionais situadas nos domínios afetivoemocionais, corrente mais comumente aceita no debate pedagógico.

Noções como competências socioemocionais, habilidades do século XXI, paradigma holístico, currículo socioemocional e abordagem transversal tornaram-se recorrentes nos debates educacionais mobilizados pelos diferentes sistemas de ensino, especialmente no período em que estivemos envolvidos nas questões atinentes à Base Nacional Comum Curricular. (CARVALHO; SILVA, 2017, p. 175).

De acordo com Santos et al. (2018), a proposta da Pedagogia baseada em competências foi justificada a partir da implantação da Lei de Diretrizes e Bases da Educação Nacional (LDBEN) n. 9.394/96, a qual estabeleceu novas orientações para a Educação Básica. Com a aprovação da nova Lei de Reforma do Ensino Médio - Lei n. 13.415/2017 (BRASIL, 2017b) -, inseriu-se na LDBEN o artigo 35-A, o qual estabeleceu em seu parágrafo $7^{\circ}$ a incorporação das Competências Socioemocionais à formação estudantil. Reproduzimos o referido parágrafo:

Os currículos do Ensino Médio deverão considerar a formação integral do aluno de maneira a adotar um trabalho voltado para a construção de seu projeto de vida e para sua formação nos aspectos físicos, cognitivos e socioemocionais. (BRASIL, 2017b).

Nas "Diretrizes Curriculares Nacionais para a formação de professores da Educação Básica” (BRASIL, 2002), o conceito de competências (cognitivas e 
socioemocionais) foi apresentado como nuclear na geração de políticas curriculares. As competências produzem o discurso da qualidade total da educação. Em nosso entendimento, o conceito de "qualidade total em educação" é sinônimo de desempenho e protagonismo individual, mais um insumo da instrumentalização do pensar, uma vez que, de acordo com os adeptos do discurso das competências, o mais preparado e o mais eficiente é aquele capaz de vencer todos os obstáculos a partir de seu esforço.

A formação por competências tem sido elemento fundamental em um número significativo de reformas curriculares nos mais variados níveis e modalidades de ensino em diversos países. Por esse mecanismo busca-se a redefinição do processo de formação contínua dos professores em torno de sua profissionalização pautada na concepção de competência profissional. A garantia do estabelecimento de um estatuto profissional da atividade docente está entre as razões mais destacadas para a adoção das competências como paradigma curricular. (DIAS; LOPES, 2003, p. 1159-60).

Nota-se que, ao justificar a Pedagogia das Competências como elemento central na formação dos indivíduos, há o deslocamento conceitual da noção de formação para a de instrumentalização, sem levar em consideração as especificidades da Educação.

A escola assume a responsabilidade de empreender ${ }^{3}$ um espaço formativo para a aquisição de saberes práticos que possam promover as competências requisitadas para que o indivíduo seja incluído no contexto social e produtivo.

Essa rápida discussão sugere uma proposta educativa sedutora da chamada Pedagogia das Competências. Diante de uma leitura rápida e simplista, quem seria contrário, por exemplo, à Pedagogia Socioemocional (para não dizer empresarial), principalmente no contexto marcado pela ressonância das chamadas metodologias ativas e eficientes?

Perrenoud (2008, p. 39) destacou-se como o principal teórico defensor da chamada Pedagogia das Competências. Em suas reflexões, o autor indaga: "Vamos à escola para adquirir conhecimentos ou para adquirir competências?". Dito de outro

3 Quem é o empresário de si? É aquele que, para ter sucesso na sociedade, deve praticar suas relações no contexto social e produtivo mediadas por valores empresariais. Competitividade, lucratividade, criatividade, praticidade são os valores requeridos ao empresário de si. E as Competências Socioemocionais são chamadas para garantir esses valores, concebeu Nicolau (2013). 
modo, pensar nas competências que a escola necessita desenvolver implica "[...] saber que tipo de seres humanos a escola quer formar, com vistas a que práticas familiares, sexuais, políticas, sindicais, artísticas, esportivas, associativas". Segundo o teórico, a formação dos indivíduos necessita ser permeada por inventários de competências capazes de guiar a prática pedagógica escolar. Para que a Educação se reformule de acordo com o exigido pela sociedade do século XXI, é necessário "[...] integrar, desde já, as abordagens por competências à formação inicial e contínua e à identidade profissional dos professores" (PERRENOUD, 2008, p. 159).

Pelo exposto acima, fica nítido como a ideia de competências na escola assemelha-se ao departamento empresarial qualquer, em que tudo pode ser administrado, controlado, programado, inclusive a subjetividade. Mas, de acordo com o debate apresentado, a Pedagogia das Competências racionais não é suficiente para formar o indivíduo integral, autônomo. É necessário desenvolver a Pedagogia das Competências Socioemocionais na escola.

\section{EDUCAR PARA ALÉM DAS COMPETÊNCIAS COGNITIVAS (OU RACIONAIS): AS COMPETÊNCIAS SOCIOEMOCIONAIS}

Como destacado anteriormente, o debate sobre as competências requeridas no século XXI tem ganhado destaque na produção acadêmica mundial como elemento essencial na definição de Políticas Públicas Educacionais.

De maneira geral, esses termos se referem, nesses documentos, à capacidade de utilização instrumental dos conhecimentos adquiridos ao longo de toda a vida, incluindo a capacidade de adquirir conhecimentos imediatamente úteis de acordo com uma concepção de mundo e de ciência derivada do pragmatismo. (SILVA, 2018, p. 87).

Relacionamento interpessoal, gerenciar as próprias emoções para atingir determinados fins, ser motivador, perceber e valorizar as emoções do outro, valorizar sentimentos diversos dos seus, agir com bom humor são as novas palavras-chave que norteiam as chamadas Competências Socioemocionais propostas pela Fundação Collaborative for Academic, Social and Emotional Learning (CASEL) e pelo Instituto Ayrton Senna, os quais almejam desenvolver a aprendizagem socioemocional já na primeira infância, até os mais elevados níveis da educação brasileira.

De acordo com a Organização para a Cooperação e Desenvolvimento Econômico [OCDE] (2015), insegurança, ansiedade, estresse - presentes em 
grande parte nos estudantes brasileiros - são elementos que não combinam com a aprendizagem, interferindo negativamente nas práticas escolares, prejudicando a formação dos estudantes.

É a partir desse quadro que as Competências Socioemocionais ganharam destaque na Base Nacional Comum Curricular (BNCC), no sentido de empreender atitudes e valores junto aos estudantes, capazes de fazê-los lidar, de maneira eficiente e imediata, com os desafios da sociedade atual, diminuindo medos e inseguranças, uma vez que uma das funções das Competências Socioemocionais é assegurar o pleno domínio da provisoriedade e do desconhecido (PERRENOUD, 2008).

A Organização para a Cooperação e Desenvolvimento Econômico (OCDE, 2015, p. 35) definiu Competências Socioemocionais como:

[...] capacidades individuais que podem ser manifestadas com um padrão consistente de pensamentos, sentimentos e comportamentos desenvolvidos por meio de experiências de aprendizagens formais e informais, e importantes impulsionadoras de resultados socioemocionais ao longo da vida do indivíduo.

Em outras palavras, é possível afirmar que as Competências Socioemocionais podem ser entendidas como "[...] resultado da soma entre desempenho socioemocional e todas as habilidades intrínsecas a ele para agir de forma funcional e adaptada à determinada cultura e contexto" (MARIN et al., 2017, p. 99).

Nota-se que, além das competências cognitivas - representadas pelas capacidades de aprender a aprender constantemente, aprender a fazer (RAMOS, 2001), para citar algumas -, o contexto contemporâneo exige ainda competências na administração das emoções individuais e do outro com os quais se convive. Essa é a fórmula para o sucesso.

Há 5 componentes da Competência Socioemocional. O primeiro é a consciência emocional de si e de outras pessoas [...]. O segundo componente é a regulação emocional que se refere ao gerenciamento apropriado das emoções. O terceiro componente é a autonomia emocional [...]. O quarto componente é o domínio de habilidades sociais [...]. O quinto componente refere-se às habilidades de vida e bem-estar [...]. (GONDIN; MORAIS; BRANTES, 2014, p. 399).

Após apresentar essa breve descrição, os defensores das Competências Socioemocionais afirmam que estas sustentam, ou melhor, estão na base das competências profissionais (OCDE, 2015). Ainda, levantam a hipótese de que há 
uma relação intrínseca entre essas duas competências - racionais e socioemocionais -, justificando a necessidade de treinar as habilidades sociais, cognitivas e profissionais para ampliar as chances de o indivíduo mais preparado inserir-se no mercado de trabalho competitivo (INSTITUTO AYRTON SENNA [IAS], 2015).

Na filosofia do Instituto Ayrton Senna, as competências cognitivas são essenciais à formação dos indivíduos, pois propiciam a instrumentalização, o raciocínio, a assimilação de ideias complexas. Aliadas a essas, temos as Competências Socioemocionais, cujos objetivos são gerenciar emoções, tomar decisões autônomas sustentando o desenvolvimento das competências profissionais (cognitivas e socioemocionais).

O argumento defendido pelo Instituto Ayrton Senna (IAS, 2016) é o de que as Competências Socioemocionais fortalecem a autoestima, desenvolvendo o clima psicológico imprescindível à adaptação do indivíduo a novos contextos e a novas aprendizagens desafiadoras.

As Competências Socioemocionais constituem uma integração de saberes e fazeres sobre si mesmas e sobre as demais, apoiando-se na consciência, na expressão, na regulação e na utilização (manejo) das emoções, cujo objetivo é aumentar o bem-estar pessoal (subjetivo e psicológico) e a qualidade das relações sociais. Em resumo, a inteligência emocional, a regulação emocional, a criatividade emocional e as habilidades sociais integram um conjunto mais amplo denominado de Competências Socioemocionais. (GONDIN; MORAIS; BRANTES, 2014, p. 400).

Na perspectiva das Competências Socioemocionais, o domínio e o desenvolvimento das emoções são idealizados como a nova panaceia aos processos de ensino e de aprendizagens considerados obsoletos. De acordo com o Instituto Ayrton Senna (IAS, 2015), a escola brasileira encontra-se numa acentuada crise. Assim, as Competências Socioemocionais surgem com a proposta de fazer dos indivíduos empresários de si, gerenciando as emoções e as capacidades cognitivas com o objetivo de se qualificarem melhor. De posse das Competências Socioemocionais, uma criança considerada ansiosa pode utilizar-se do domínio da regulação emocional, transformá-la em competências racionais, impulsionando o processo de ensino e de aprendizagem (IAS, 2015). Essa é a lógica da Pedagogia das Competências Socioemocionais.

Ampliando o debate, em "Sobre o desenvolvimento das Competências Socioemocionais nas escolas", o Instituto Ayrton Senna (IAS, 2015) pontuou que 
os Programas de Aprendizagem Socioemocionais produzem resultados satisfatórios na promoção do desenvolvimento de competências consideradas essenciais à formação dos estudantes.

De que forma esses resultados são verificados? A partir de um conjunto de testes padronizados de aferição das Competências Socioemocionais. Para se ter uma ideia do que estamos tratando, no Brasil, em 2013, foi apresentado um instrumento de avaliação em larga escala para mensurar as Competências Socioemocionais, elaborado pelo IAS e pela OCDE, com a parceria da Secretaria Estadual de Educação do Rio de Janeiro. O estudo é resultado de um projeto-piloto cujo objetivo foi mensurar as Competências Socioemocionais dos alunos com o intuito de apontar se o desenvolvimento socioeconômico está ou não relacionado ao desempenho acadêmico. De acordo com seus proponentes, o modelo de classificação do instrumento de avaliação é o mesmo escolhido pela OCDE, ou seja, o Big Five. A partir da matriz de avaliação das Competências Socioemocionais, há dimensões estrategicamente relacionadas ao desenvolvimento do indivíduo. As críticas a esse modelo de avaliação das Competências Socioemocionais são tecidas por Smolka et al. (2015, p. 236), ao afirmarem que:

Separar, para fins de mensuração, os aspectos socioemocionais dos aspectos cognitivos, isolando habilidades e traços de personalidade pré-definidos a partir de um constructo tão questionado, tende a congelar e tipificar comportamentos, estabelecendo correlações que, mais uma vez, simplificam a complexidade e a dinâmica do desenvolvimento humano e ocultam a condições e contradições vivenciadas e enfrentadas por professores, alunos e seus familiares no cotidiano da instituição escolar.

Os adeptos da Pedagogia das Competências Socioemocionais afirmam que o aprendizado de habilidades cognitivas efetuado pela escola tradicional ainda é muito restrito e desconectado da realidade dos estudantes. Assim, o aprendizado mediado por Competências Socioemocionais é a nova aposta sedutora da escola que se pretende inovadora e mais integradora (OCDE, 2015).

Desse modo, o perfil do estudante eleito pela Organização para a Cooperação e Desenvolvimento Econômico (OCDE) necessita contemplar as Competências Socioemocionais, como: ser colaborativo, afável, autônomo, que saiba intervir em conflitos, tenha autocontrole, potencializando sua capacidade adaptativa aos diferentes contextos requeridos pela sociedade tecnológica. 
Quem é o competente? Em nossas sociedades é aquele que possui um saber determinado institucionalmente reconhecido graças ao qual pode não só falar e agir pelos outros, mas ainda, e sobretudo, exclui outros do direito de ser sujeitos de seus discursos e de suas ações. Quem é o incompetente? Em nossas sociedades é aquele que foi expropriado de sua condição de sujeito e convertido em objeto do saber e da prática dos competentes. Sob a auréola da neutralidade e da objetividade dos conhecimentos técnico-científicos, a competência é um poderoso elemento ideológico para justificar (ocultando) o exercício da dominação. (CHAUÍ, 2014, p. 113).

Daí a necessidade constante de questionamentos acerca dos reais interesses das fundações empresariais na elaboração de políticas públicas educacionais permeadas pela Pedagogia das Competências Socioemocionais.

Não é por acaso que a definição de competências para a OCDE (2015, p. 35) engloba as "[...] capacidades individuais que podem ser manifestadas em comum padrão consistente de pensamentos, sentimentos e comportamentos [...] e importantes impulsionadoras de resultados socioeconômicos ao longo da vida do indivíduo".

As justificativas para a implantação do modelo das Competências Socioemocionais na educação brasileira são respaldadas pelo documento "Competências para o progresso social: o poder das competências socioemocionais", produzido pela Organização para a Cooperação e Desenvolvimento Econômico (OCDE), publicado em 2015.

Segundo os organizadores, é necessário que os indivíduos desenvolvam Competências Socioemocionais desde a Educação Infantil, para serem bem-sucedidos em suas vidas. Desse modo, o simples fato de os indivíduos desenvolverem Competências Socioemocionais já possibilitaria a eles "[...] o sucesso dentro da escola e fora dela, indicando nas entrelinhas um êxito no mercado de trabalho" (LIMA, 2018, p. 17).

É necessário acrescentar que a versão preliminar do documento acima citado foi apresentada em 2014, no evento intitulado "Educar para as competências do século XXI", em que se reuniram os representantes do Instituto Nacional de Estudos e Pesquisas Educacionais "Anísio Teixeira" (INEP), da OCDE e do IAS.

Nota-se que a crescente ênfase na Pedagogia das Competências Socioemocionais promovida pelas instituições privadas aparece como o novo - e único caminho - para a escola superar seus desafios. A orientação básica para 
o indivíduo atingir a formação almejada é "[...] o incentivo das Competências Socioemocionais como perseverança, responsabilidade e motivação" (OCDE, 2015, p. 19).

Ao apontar a importância das Competências Socioemocionais nos processos formativos, a OCDE destacou que essas competências privilegiam crianças e jovens menos favorecidos pelo sistema econômico, pois garantem a formação de "[...] cidadãos engajados, saudáveis, responsáveis e felizes" (OCDE, 2015, p. 28).

Sedutor, o texto da OCDE conquista a muitos com uma rápida leitura, pois é raro alguém ir contra a afirmação de um sujeito integral, englobando o cognitivo e o socioemocional. Entretanto, ao ler um pouco mais atentamente, começa a se perceber o discurso "humanizado do capital", direcionando as ações às famílias desfavorecidas economicamente. Ao estampar o envolvimento de uma organização para o desenvolvimento econômico, fica evidente a preocupação na formação dos indivíduos adequados às novas demandas do mundo do trabalho, no processo de reprodução da sociedade capitalista. (LIMA, 2018, p. 18).

Percebemos que o ideário economicista e empresarial é transportado para o interior das escolas como fim último da realização humana, evidenciando o discurso de que competência gera competência.

Desde a mais tenra idade, as nossas crianças são incentivadas a serem competitivas. E os professores também. De que forma? A partir de reformas educacionais que privilegiam a instrumentalização da formação mediada pelas Competências Socioemocionais: cooperação, autocontrole emotivo, capacidade de enfrentar problemas que estão além do domínio cognitivo, autodisciplina, autoeficácia, controle da agressividade, cordialidade, resiliência e empatia, entre outras.

Pelo exposto até aqui, vimos como a OCDE (2015) e o IAS (2015) procuram legitimar as Competências Socioemocionais junto às políticas curriculares educacionais, elegendo o perfil desejado para que os estudantes atinjam a sonhada formação integral.

Smolka et al. (2015) pontuaram que aqueles que não se encaixarem no novo modelo de Competências Socioemocionais podem ser excluídos do processo educativo vendido como democrático.

Caetano (2016) e Cóssio (2015) apontaram que a Pedagogia das Competências Socioemocionais é adaptacionista, uma vez que prioriza competências consideradas úteis à sociabilidade imposta pelo capital transnacional. Para os autores acima 
citados, as organizações privadas brasileiras defendem a educação na perspectiva neoliberal, transferindo a lógica empresarial aos bancos escolares, direcionando, desse modo, as políticas públicas educacionais.

A vinculação da formação de competências a programas de treinamento (coaching) ou às chamadas metodologias ativas comprova que não se trata de um processo de formação e desenvolvimento humano pleno, mas da produção de autômatos programados para reagir em conformidade com as expectativas sociais. As pessoas devem controlar as emoções como dirigir um automóvel sem precisar pensar no que estão fazendo para que possam funcionar adequadamente nas escolas, no trabalho ou na vida. (SILVA, 2018, p. 151).

Como destacado acima, o objetivo principal da Pedagogia das Competências Socioemocionais não é promover a formação integral dos indivíduos, mas administrar as emoções e os afetos, controlando a subjetividade, convertendo as escolas em empresas, em que operam os "mais capacitados", os empreendedores. Assim, todo tipo de crítica e de capacidade de resistências ao status quo não cabe no modelo das Competências Socioemocionais.

Nesse contexto, formação é sinônimo de qualificação, de capacitação, sinônimo de desenvolvimento de Competências Cognitivas e Socioemocionais, inserindo nas estruturas curriculares comportamentos requeridos pelo mercado neoliberal, instaurando "[...] leis e regulamentações das parcerias público-privadas que levam ao empobrecimento do processo pedagógico" (LIMA, 2018, p. 61).

Manfredi (2010, p. 4), em concordância com Kuenzer (1998), pontuou que o modelo de Competências Socioemocionais, em sua forma homogeneizadora e padronizadora, "[...] destrói a diversidade. A lógica do modelo de competências é disciplinadora e fabril. É o modelo de organização da fábrica traduzido para a organização escolar".

Diante da amplitude que caracteriza a temática, partimos do pressuposto de que, para além da reforma educacional, é necessária a reforma do pensamento. Nesse sentido, buscamos a fundamentação filosófica permeada pelo pensamento adorniano no sentido de evidenciar a Pedagogia Socioemocional como resultado da Semiformação (Halbbildung), ou melhor, da negação da formação cultural (Bildung). Acrescentamos que o pensamento reflexivo é um referencial crítico que ultrapassa os limites instrumentais das reformas educacionais atuais. 


\section{VIDA DANIFICADA E DECLÍNIO DA FORMAÇÃO: UM DIAGNÓSTICO CONTEMPORÂNEO}

O tema da formação cultural (Bildung), ou melhor, de seu depauperamento é um dos elementos presentes no pensamento adorniano.

Em meio às reflexões sobre a instrumentalização das subjetividades na contemporaneidade, a relação entre técnica, Semiformação (Halbbildung) e reificação da consciência emerge com força na série de aforismos em Minima Moralia. Desde já, pontuamos que a Semiformação (Halbbildung) é o travamento da experiência; o pensamento reflexivo é empobrecido, ou melhor, negado no contexto escolar. O imediatismo e a fragmentação das vivências são a norma atual. A inaptidão à experiência promovida, entre outros fatores, por pedagogias que apenas adaptam, produz a consciência coisificada - a exemplo da Pedagogia das Competências Socioemocionais -, ocultando os elementos empobrecedores do pensamento.

O processo de coisificação dos indivíduos mediado pela racionalidade instrumental e por metodologias reificadoras que tornam as pessoas semelhantes às máquinas foi anotado por Adorno (2001), no aforismo "Devagar e sempre". O andar apressado das pessoas nas ruas, o culto à velocidade, o esporte exacerbado, a reificação do pensamento a partir do desenvolvimento da Semiformação (Halbbildung) configura a produção da nova subjetividade na contemporaneidade. Há o predomínio do indivíduo ajustado, manipulável, transformado em mero objeto e sujeito à dominação.

À época de sua liquefação, Adorno (2001) concebeu a forma assumida pelo indivíduo comparável à mônada. O filósofo atesta duas características fundamentais da individualidade na sociedade reificada. Primeira, sua condição de célula apartada do contato ativo com o meio social em que está envolvido. Segunda, a diferença assumida pelo indivíduo de exercer a crítica e ocupar o lugar que, ao mesmo tempo, já está implicado pelo contexto do qual ele pretende distanciamento.

No caso da Pedagogia das Competências Socioemocionais, ao indivíduo é atribuída toda a responsabilidade por sua (semi)formação: cursos rápidos, capacitações, ser empreendedor de si, aprender a aprender constantemente (não importando o aprender a refletir). Caso não se adapte a esse contexto - mesmo 
com todas as possíveis oportunidades a ele oferecidas -, é considerado um fracassado. A norma atual é protagonizar a existência por meio das competências e habilidades, mesmo que por processos de mecanismos instrumentais.

Com efeito, em uma época cujas palavras-chave são projeto, motivação, iniciativa, eficiência, flexibilidade não surpreende a avaliação positiva de indivíduos ativos. Não obstante a ênfase dada à flexibilidade, juntas, todas as expressões supracitadas constituem o mantra do paradigma produtivo atual que perpassa inteiramente a existência individual, submetendo-a a novas coações. (HAN, 2017, p. 101).

Pelo exposto, a cultura não promove a emancipação do indivíduo, mas faz dele dócil e impotente representante último da Semiformação (Halbbildung). Adorno (2001) se empenhou a denunciar a deficiência da formação dos indivíduos na contemporaneidade.

Aparece aqui a imagem do indivíduo ajustado, manipulável - como ocorre na Pedagogia das Competências Socioemocionais -, o qual é transformado em mero objeto e sujeito à dominação. De acordo com Adorno (2001, p. 154): "Mediante à dissolução no indivíduo de todo o mediador, graças ao qual este pôde ser uma parte do sujeito social, ele empobrece-se, regride ao estado de simples objeto social".

O tema da Semiformação (Halbbildung) aparecerá mais uma vez no aforismo "Jantar de gala". Nesse, Adorno (2001) discutiu um dos esquemas-chave da Indústria Cultural: a repressão pulsional. Esse mecanismo está associado à oferta incontrolável de produtos que são direcionados aos consumidores e que, ao serem apresentados como "novidades", despertam nas pessoas a falsa expectativa de que seus desejos serão totalmente atendidos: o novo computador, a nova pílula mágica emagrecedora, a alimentação mais saudável, a metodologia mais ativa, a didática mais inovadora, a competência mais requisitada quando, na verdade, não passam da eterna repetição do mesmo, do sempre igual.

Nessa complexa rede de domesticação dos indivíduos, a própria cultura coisifica-se, sendo devolvida para o seio da sociedade apenas como produto para o consumo imediato. No campo das Competências Socioemocionais, conduz-se a subjetividade ao definhamento que extingue as possibilidades de resistência e de inconformismo. A cultura é reificada, desencadeando um processo gradativo que a levará a ser fetichizada em bens de consumo, em mais um modismo. 
O que se espera é que as pessoas tenham reações emocionais previsíveis e não apresentem alterações de humor repentinas. Nesse fato não se mencionam os atributos de personalidade desejáveis, mas os indesejáveis, do indivíduo emocionalmente instável, preocupado, irritadiço, introspectivo, impulsivo, não autoconfiante, podendo manifestar depressão e desordens de ansiedade. (SANTOS et al., 2018, p. 141).

Visando à formação de indivíduos adaptados, a racionalidade instrumental objetiva massificar as subjetividades, disseminando, por meio da relação de poder, valores, modelos e necessidades supostamente universais, normatizando as consciências ao ponto de formar indivíduos que, ausentes do processo reflexivo, e tolhidos de seu poder de escolha, aderem irrefletidamente aos simulacros da dominação. Temos presente, então, mecanismos que engendram o processo de Semiformação (Halbbildung).

Adorno (2001) denunciou a realidade que se abre aos indivíduos enquanto processo que não carrega mais as experiências intercambiáveis entre eles, mas se pauta na brevidade do novo, no vácuo subjetivo da racionalidade, tornando a realidade empobrecida.

Por toda a Minima Moralia, há referências de Adorno ao Eu como o diretor da empresa que deve coordenar e gerenciar as instâncias divergentes, administrando os conflitos com o objetivo de, com a otimização do funcionamento da empresa, melhorar a publicidade do produto, promovendo assim, sua melhor valorização no mercado. (MORAES, 2004, p. 86).

No campo do debate sobre Competências Socioemocionais, nota-se a configuração do modelo educativo pautado na racionalidade instrumental, uma rede massificante que visa a todo instante subtrair o que há de singular no indivíduo por modelos identitários, de modo a perpetuar a Semiformação (Halbbildung).

Há então de se pensar nas possibilidades da Educação, tendo em vista a experiência como elemento do processo formativo no enfrentamento dos mecanismos empobrecedores da cultura, provocando reflexões sobre os possíveis caminhos para o pensamento crítico. O conceito de experiência em Adorno (1996) comporta a dimensão crítico-formativa. Desse modo, a dialética experiência e pensamento é preservada, assumindo aquilo que o autor denominou de experiência filosófica. A experiência apartada do pensamento é sinônimo de Semiformação (Halbbildung), de empobrecimento do pensar. 
As artificiosas apologias do "espírito empreendedor" das Competências Socioemocionais que povoam as orientações educacionais esvaziam o potencial de resistência e de crítica do docente e do discente.

A educação, então, necessita promover seu potencial emancipatório ao manter a tensão inevitável entre adaptação e inadequação, sendo esta última essencial à formação (Bildung), como necessário distanciamento do fenômeno educativo, para que o pensamento não se reduza ao conformismo e às propostas semiformativas travestidas de supostas novidades.

[...] traduzir a Bildung pela expressão Formação Cultural é uma proposta que garante sua complexidade, pois é revestida por um significado duplo, a saber: o ideal pedagógico formativo assentado em solo institucional, cultural, e o ideal de um autocultivo, não necessariamente atrelado a uma instituição formativa. (NICOLAU, 2013, p. 39).

A impossibilidade de reflexão na escola repõe a mesma lógica presente na sociedade instrumental, perpetuando no âmbito educacional a Semiformação (Halbbildung) do indivíduo, tornando-o ainda mais distante das possibilidades de reflexão sobre os determinantes do estado atual da Educação.

A resistência em Adorno é o resultado depurado da exigência de se manter a tensão entre pensamento e realidade.

Nesse sentido, é preciso aplicar toda energia para que "a educação seja uma educação para a contradição e para a resistência" no existente, para se contradizer e resistir como modo de ir além do plano da reconstrução cultural e da vigência da Semiformação, referindo-se ao plano da vida real efetiva. (MAAR, 2003, p. 473).

\section{CONSIDERAÇÕES INCONCLUSIVAS}

A partir de uma visão crítica e de resistência, este artigo tratou do debate sobre a Pedagogia das Competências Socioemocionais e o conceito de (semi) formação nele presente.

Competências, empreendedorismo, habilidades e saberes são termos empregados pelos defensores do modelo das Competências Socioemocionais na escola, sem se vincularem a qualquer teoria pedagógica.

Pela exposição desenvolvida, notamos o quanto a Pedagogia das Competências Socioemocionais atende a dois pilares da educação mundial: "aprender a conviver" e o "aprender a ser" (DELORS, 1998). 
Vimos como as instituições empresariais - tais como o Instituto Ayrton Senna - associam educação à produtividade como única proposta formativa, aplicando os princípios da gestão empresarial à formação educacional, reduzindo a escola à eficiência dos meios instrucionais, gerando competição e Semiformação (Halbbildung), despreocupando-se com a universalização do patrimônio cultural da humanidade e com a formação integral dos indivíduos. Nesse sentido, aos currículos educacionais são instituídas diretrizes emanadas da OCDE e do Instituto Ayrton Senna, disciplinando a vida social e produtiva.

De acordo com o IAS, as propostas curriculares atuais devem ser formuladas de acordo com as políticas neoliberais, instaurando novos modos de experienciar a realidade, instituindo métodos pedagógicos pautados por Competências Socioemocionais adequados aos "novos métodos" de trabalho caracterizados pela ausência do pensamento reflexivo, uma vez que a pedagogia "[...] encontra sua melhor expressão na Pedagogia das Competências" (KUENZER, 2004, p. 9).

Hypólito (2019) afirmou que a Pedagogia das Competências prioriza a formação de um "novo" profissional baseando-se em esquemas cognitivos e socioemocionais cujo objetivo é adaptar o indivíduo às constantes mudanças do mercado global.

Nota-se que o discurso da formação integral na educação escolar engloba a formação de competências cognitivas e socioemocionais alinhadas à naturalização das relações capitalistas e à governamentalização da vida.

Esse pressuposto é evidenciado nas competências gerais 6, 7 e 8 da Base Nacional Comum Curricular (BNCC), que se referem, respectivamente, ao "projeto de vida pessoal", "ao cuidado de si mesmo" e à "faculdade de gerenciar as próprias emoções".

Os muros entre a empresa e a escola são rompidos, e o papel desta passa a ser de produtora de competências adequadas ao contexto do capital neoliberal.

Há o risco de o docente se tornar um mero monitor educacional, e o material pedagógico ser mais importante, reduzindo a formação ao tecnicismo, privilegiando as privatizações e as culturas neoconservadoras. Essa é a lógica do alinhamento da educação às recomendações internacionais. Assim, o pressuposto "Vamos à escola para adquirir competências" (PERRENOUD, 2008) soa-nos de forma provocativa, denunciando que a lógica das Competências Socioemocionais é enfraquecedora do pensamento crítico. 
Em Adorno (1996, p. 391), a educação que se faz urgente é a educação para a resistência e para a contradição, "[...] pois a formação nada mais é que a cultura tomada pelo lado de sua apropriação subjetiva".

No debate sobre Competências Socioemocionais, explicitou-se que formação é sinônimo de aquisição de competências "[...] conhecimentos, valores, atitudes e habilidades" (IAS, 2015, p. 9). Nessa perspectiva, formação é sinônimo de treinamento, preparando o indivíduo para lidar com o previsível, com o padronizado.

E as Competências Socioemocionais atendem esses pressupostos. Dito de outro modo, há o desenvolvimento do trabalho menos voltado à reflexão, e mais voltado a comportamentos: o indivíduo tem de ser resiliente, saber lidar e resolver problemas sob pressão. Transfere-se ao indivíduo a responsabilidade de fazer sua formação: ser flexível, adaptável, moldável. As Competências Socioemocionais retiram o nexo crítico e impõem o aprender a fazer. O objetivo é a modernização escolar. Todo o paradigma empresarial se faz presente nesse debate. Não é essa perspectiva que defendemos.

Na perspectiva das Competências Socioemocionais, o professor bem formado é aquele que sabe trabalhar com o material didático padronizado. Ou seja, retira-se do professor a intelectualidade no campo da Educação. Isso está longe do que entendemos por formação (Bildung). Destaca-se que o declínio da formação na escola está ligado à impossibilidade de se estabelecer uma autorreflexão com o próprio pensamento.

Nos recortes tematizados, procurou-se debater que a aprendizagem pautada unicamente por competências e habilidades depaupera as possibilidades de crítica e de resistência à racionalidade instrumental.

Diante do exposto, entende-se que o currículo escolar está além da dimensão meramente prescritiva e padronizada, que indica conteúdos específicos, formas, métodos e objetivos de aprendizagem supostamente aplicáveis, como defende a Base Nacional Comum Curricular (BRASIL, 2017a).

Assim, a autorreflexão é o caminho de resistência aos mecanismos empobrecedores do pensamento crítico.

A discussão proposta passa pela crítica de análises superficiais presentes nas propostas formativas contemporâneas, em que resistência e inconformismo são maneiras possíveis de manifestação da individualidade que só pode ser pensada 
em sua negatividade. Conclui-se que a resistência em Adorno (1996) é o resultado depurado da exigência de se manter a tensão entre pensamento e realidade.

\section{REFERÊNCIAS}

ADORNO, Theodor W. Minima Moralia: reflexões sobre a vida danificada. Tradução de Artur Morão. São Paulo: Edições 70, 2001.

ADORNO, Theodor W. Teoria da Semiformação. Educação e Sociedade, Campinas, São Paulo, v. 17, n. 56, p. 388-411, set./dez. 1996.

BRASIL. Ministério da educação. Base Nacional Comum Curricular: educação é base. Brasília-DF: MEC, 2017a.

BRASIL. Lei n. 13.415, de 16 de fevereiro de 2017. Altera as Leis n. 9.394, de 20 de dezembro de 1996, que estabelece as diretrizes e bases da educação nacional, e 11.494, de 20 de junho 2007, que regulamenta o Fundo de Manutenção e Desenvolvimento da Educação Básica e de Valorização dos Profissionais da Educação, a Consolidação das Leis do Trabalho- CLT, aprovada pelo Decreto-Lei no 5.452, de 1ㅇde maio de 1943, e o Decreto-Lei no 236, de 28 de fevereiro de 1967; revoga a Lei no 11.161, de 5 de agosto de 2005; e institui a Política de Fomento à Implementação de Escolas de Ensino Médio em Tempo Integral. Brasília-DF, 2017b. Disponível em: http://www.planalto.gov.br/ ccivil_03/_Ato2015-2018/2017/Lei/L13415.htm. Acesso em: 31 jan. 2021.

BRASIL. Resolução CNE/CP n. 1, de 18 de fevereiro de 2002. Institui Diretrizes Curriculares Nacionais para a Formação de Professores da Educação Básica, em nível superior, curso de licenciatura, de graduação plena. Brasília-DF, 2002. Disponível em: http://portal.mec. gov.br/seesp/arquivos/pdf/res1_2.pdf. Acesso em: 4 out. 2021.

CAETANO, Maria. A proposta do Instituto Ayrton Senna para a educação do século XXI ou uma velha proposta com nova roupagem. Revista FAED-UNEMAT, Cáceres, MT, v. 24, n. 2, p. 113-33, set./dez. 2016. Disponível em: www2.unemat.br.revistafaed.content.vol_24. artigo_24. Acesso em: 15 nov. 2019.

CARVALHO, Rodrigo; SILVA, Roberto. Currículos socioemocionais, habilidades do século XXI e o investimento econômico em educação: as novas políticas curriculares em exame. Educar em Revista, Curitiba, v. 2, n. 63, p. 173-190, jan./maio 2017. Disponível em: http:// www.scielo.br/pdf/er/n63/1984-0411-er-63-00173.pdf. Acesso em: 16 dez. 2019.

CHAUÍ, Marilena. A ideologia da competência. In: ROCHA, André (Org.). Escritos de Marilena Chauí. São Paulo: Fundação Perseu Abramo, 2014. p. 113-21. 
CóssıO, Maria. Agenda transnacional e governança nacional: as possíveis implicações na formação e no trabalho docente. Revista E-curriculum, São Paulo, v. 13, n. 4, p. 616-40, out./dez. 2015. Disponível em: https://revistas.pucsp.br/curriculum/article/view/25957. Acesso em: 20 nov. 2019.

DELORS, Jacques. Educação: um tesouro a descobrir. Relatório para a UNESCO da Comissão Internacional sobre Educação para o século XXI. 3. ed. Brasília, DF: MEC; UNESCO, 1998.

DIAS, Rosane; LOPES, Alice. Competências na formação de professores no Brasil: o que (não) há de novo. Educação e Sociedade, Campinas, v. 24, n. 85, p. 1155-77, set./dez. 2003. Disponível em: http://www.cedes.unicamp.br. Acesso em: 10 nov. 2019.

GONDIN, Sônia Maria Guedes; MORAIS, Franciane Andrade; BRANTES, Carolina dos Anjos Almeida. Competências socioemocionais: fator-chave no desenvolvimento de competências para o trabalho. Revista Psicologia, Organizações e Trabalho, Florianópolis, SC, v. 14, n. 4, p. 394-406, out./dez. 2014. Disponível em: http://pepsic.bvsalud.org/pdf/ rpot/v14n4/v14n4a06.pdf. Acesso em: 10 dez. 2019.

HAN, Byung-Chul. Sociedade do cansaço. Tradução de Ênio Paulo Giachini. 2. ed. Petrópolis: Vozes, 2017.

HYPÓLITO, Álvaro M. BNCC, agenda global e formação docente. Revista Retratos da Escola, Brasília,v. 13, n. 25, p. 187-201, jan./maio 2019. Disponível em: http://www.esforce.org. br. Acesso em: 3 nov. 2019.

INSTITUTO AYRTON SENNA [IAS]. Competências socioemocionais: material para discussão. São Paulo: IAS, 2015. Disponível em: https://institutoayrtonsenna.org.br/ content/dam/institutoayrtonsenna/radar/estante-educador/COMPET\%C3\%8ANCIASSOCIOEMOCIONAIS_MATERIAL-DE-DISCUSS\%C3\%830_IAS_v2.pdf. Acesso em: 4 out. 2019.

INSTITUTO AYRTON SENNA [IAS]. Sobre o desenvolvimento de competências nas escolas. São Paulo: Edulab21; Insper, 2016. Disponível em: https://www.insper.edu.br/wp-content/ uploads/2020/07/IAS_Livro_TomandoNota.pdf. Acesso em: 4 out. 2021.

KUENZER, Acácia. Competência como práxis: os dilemas da relação entre teoria e prática na educação dos trabalhadores. Boletim Técnico do Senac, v. 3, n. 30, p. 81-93, 2004. Disponível em: https://www.bts.senac.br/bts/article/view/501. Acesso em: 4 out. 2021.

KUENZER, Acácia Z. As mudanças no mundo do trabalho e a educação: novos desafios para a gestão. In: FERREIRA, Naura S. Gestão democrática da educação: atuais tendências, novos desafios. São Paulo: Cortez, 1998. p. 136-50. 
LIMA, Lígia C. Competências socioemocionais na educação: um estudo sobre a sociabilidade requerida pelo capital no século XXI. 2018. 135 f. Dissertação (Mestrado em Educação) - Universidade Federal de Santa Catarina, Florianópolis, 2018.

MAAR, W. L. Adorno, Semiformação e educação. Educação e Sociedade, Campinas, SP, v. 83, n. 24, p. 459-76, ago./set. 2003. Disponível em: http://www.cedes.unicamp.br. Acesso em: 23 nov. 2019.

MANFREDI, Silvia M. Uma política de certificação profissional orientada para a inclusão social. Revista Faculdade Senac, São Paulo, v. 3, n. 1, p. 201-15, jan./abr. 2010. Disponível em: http://www.revista.facsenac.com.br. Acesso em: 9 nov. 2019.

MARIN, Ângela Helena; SILVA, Cecília Tonial; ANDRADE, Erica Isabel Dellatorre; BERNARDES, Jade; FAVA, Débora Cristina. Competência socioemocional: conceitos e instrumentos associados. Revista brasileira de terapias cognitivas, Porto Alegre, RS, v. 13, n. 2, p. 92-103, 2017. Disponível em: http://pepsic.bvsalud.org/pdf/rbtc/v13n2/ v13n2a04.pdf Acesso em: 2 dez. 2019.

MORAES, Alexandre L. Indivíduo e resistência: sobre a anulação da individualidade e a possibilidade de resistência do indivíduo em Adorno e Horkheimer. 2004. Dissertação (Mestrado em Educação) - Universidade de Campinas, Campinas, SP, 2004.

NICOLAU, Marcos Fábio Alexandre. O conceito de formação cultural (bildung) em Hegel. 2013. 205 f. Tese (Doutorado) - Universidade Federal do Ceará, Fortaleza, CE, 2013.

ORGANIZAÇÃO PARA COOPERAÇÃO E DESENVOLVIMENTO ECONÔMICO [OCDE]. Estudos da OCDE sobre competências para o progresso social: o poder das competências socioemocionais/OCDE. São Paulo: Fundação Santillana, 2015. Disponível em: https:// www.opee.com.br/competencias-para-o-progresso-social/. Acesso em: 4 out. 2021.

PERRENOUD, Phillipe. Dez novas competências para ensinar. Porto Alegre, RS: Artmed, 2008. RAMOS, Marise N. A pedagogia das competências: autonomia ou adaptação? São Paulo: Cortez, 2001.

SANTOS, Maristela Volpe; SILVA, Talita Fernanda; SPADARI, Gabriela Fabbro; NAKANO, Tatiana de Cássia. Competências socioemocionais: análise da produção científica nacional e internacional. Revista Interinstitucional de Psicologia, Uberlândia, v. 1, n. 11, p. 4-10, dez. 2018. Disponível em: http://pepsic.bvsalud.org/pdf/gerais/v11n1/02.pdf Acesso em: 10 dez. 2019.

SILVA, Márcio M. A formação de competências socioemocionais como estratégia para captura da subjetividade da classe trabalhadora. 2018. 169 f. Tese (Doutorado em 
Educação Escolar) - Universidade Estadual Paulista "Júlio de Mesquita Filho", Araraquara, SP, 2018.

SMOLKA, Ana Luiza Bustamante; LAPLANE, Adriana Lia Friszman; MAGIOLINO, Lavinia Lopes Salomão; DAINEZ, Débora. O problema da avaliação das habilidades socioemocionais como política pública: explicitando controvérsias e argumentos. Educação e Sociedade, Campinas, v. 36, n. 130, p. 219-42, mar. 2015. Disponível em: https://www.scielo.br/j/ es/a/WTmS8JRvXxwRQZKjB7GdLJH/abstract/?lang=pt Acesso em: 13 out. 2019.

\section{Sobre o autor:}

Ademir Henrique Manfré: Doutor e mestre em Educação pela Universidade Estadual Paulista (UNESP). Especialista em Psicopedagogia Clínica e Psicopedagogia Institucional. Psicanalista Clínico pela Escola de Psicanálise de Curitiba. Graduado em Pedagogia pela UNESP. Leciona junto aos cursos de graduação (presencial e EAD) em Pedagogia, Letras, Matemática, História e Química da Faculdade de Artes, Ciências Letras e Educação de Presidente Prudente (FACLEPP). Parecerista técnico-científico ad hoc. Revisor do periódico Guia do Estudante da Editora Abril. E-mail: ademirmanfre@yahoo.com.br, ORCID: https://orcid.org/0000-0002-2067-4657 